\title{
Influence of reaction products on the selective oxidation of ethene
}

\author{
E.P.S. Schouten, P.C. Borman, K.R. Westerterp* \\ Chemical Reaction Engineering Laboratories, Department of Chemical Engineering, University of Twente, P.O. Box 217, \\ 7500 AE Enschede, Netherlands \\ Received 22 February 1995; accepted 16 June 1995
}

\begin{abstract}
The kinetics of the selective oxidation of ethene in air over an industrial silver on $\alpha$-alumina catalyst were studied. Special attention was paid to the influence of the reaction products on the reaction rates of epoxidation and complete combustion. Kinetic data were obtained in two different types of internal recycle reactor and in a cooled tubular reactor, and were fitted separately to several reaction rate expressions based on different kinetic models. A Langmuir-Hinshelwood mechanism, in which adsorbed ethene reacts with adsorbed molecular oxygen, was chosen as the best kinetic model. The reaction products compete for adsorption on the active sites and reduce the rates of both reactions. Carbon dioxide enhances the selectivity towards ethene oxide, whereas water has almost no influence on the selectivity. The fitting of the three individual data sets obtained in the three reactors results in accurate, but different, reaction rate expressions, whereas the fitting of the three data sets simultaneously results in less accurate reaction rate expressions. The systematic deviations found may be explained, to some extent, by differences in the operating regimes in each reactor. The main reason for the deviations is probably the different catalyst activities in the three reactors caused by poisoning. The effect of the addition of products to the feed on the behaviour of the cooled tubular reactor can be described reasonably well by a mathematical model in which the kinetic equations obtained in the laboratory reactors are incorporated. The results of these simulations are sensitive to the kinetics used.
\end{abstract}

Keywords: Kinetics; Cooled tubular reactor; Silver catalyst; Discrimination

\section{Introduction}

We have investigated the behaviour of cooled tubular reactors both theoretically and experimentally. The separate determination of kinetic and heat transport parameters and a model to predict the reactor performance at different operating conditions should lead to the adequate development of a commercial reactor without the need to test an empirical pilot plant of cooled tubes with catalyst [1]. The selective oxidation of ethene (see Fig. 1) was used as a model reaction system to compare model predictions with experimentally determined temperatures and concentrations in a cooled tubular reactor. This reaction system was chosen because of the high exothermic heat effects and the selectivity problems involved. A silver on $\alpha$-alumina Raschig ring was used as catalyst. Under epoxidation conditions, the consecutive combustion of ethene oxide (reac-

* Corresponding author. tion (3)) is considered to be negligible [2-4]. Therefore a parallel reaction scheme of epoxidation (reaction (1)) and complete combustion (reaction (2)) of ethene remains. Few quantitative data are available in the literature on the kinetics of these two reactions; moreover,

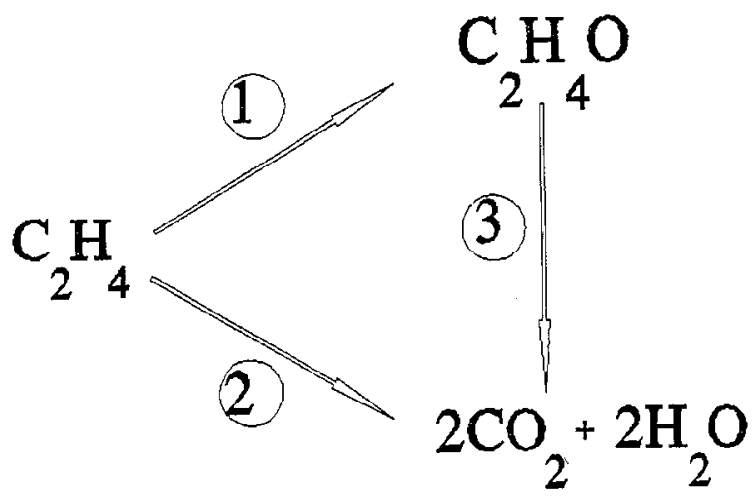

Fig. 1. Reaction scheme for the oxidation of ethene. $\Delta H_{1}=-105 \mathrm{~kJ}$ $(\mathrm{mol} \mathrm{E})^{-1} ; \Delta H_{2}=-1323 \mathrm{~kJ}(\mathrm{~mol} \mathrm{E})^{-1} ; \Delta H_{3}=-1218 \mathrm{~kJ}(\mathrm{~mol}$ E) -1 . 
the published data differ because the catalyst formulation and/or operating conditions are not comparable. Therefore we have been forced to study the kinetics ourselves.

Previously, we have reported a significant influence of the reaction products, $\mathrm{CO}_{2}, \mathrm{H}_{2} \mathrm{O}$ and $\mathrm{EO}$, on the reaction rates [4]. In this study, kinctic data measurcd in a tubular reactor and data from two recycle reactors are used to determine the kinetics; special attention is paid to the influence of the reaction products. The influence of the reaction products is also studied by their addition to the feed in a cooled tubular reactor; the effect of the products on the behaviour of the reactor is determined both experimentally and theoretically.

\section{Literature}

Silver is a good catalyst for ethene epoxidation because it forms weak bonds with ethene and oxygen. A typical catalyst consists of silver, promoted by oxidized alkali and alkaline earth metals such as potassium, barium and caesium, dispersed on a highly pure $\alpha$-alumina carrier. In the literature, there is no agreement on the mechanisms of the catalysed reactions. The discussion is focused on the forms of oxygen present on the catalyst surface and which form is responsible for epoxidation and/or total combustion. Further matters which remain to be solved are whether ethene reacts in the gas phase or in an adsorbed activated state, the way in which the reaction products are adsorbed on the catalyst surface and their influence on the reaction rates.

\subsection{Mechanism of ethene epoxidation}

Three types of oxygen are expected to be present on the catalyst surface: molecular oxygen, atomic oxygen and subsurface oxygen. Subsurface oxygen is not expected to be involved in the reactions and probably reduces oxygen atom bonding with the surface [5-7]. The mechanism originally proposed [8] considers that molecular oxygen is responsible for epoxidation and atomic oxygen for total combustion. After dissociation of one molecule of oxygen, two oxygen atoms are formed, one of which is assumed to bc consumed in the epoxidation reaction while the other remains bound to the surface. If only atomic oxygen is involved in the total combustion reaction, six oxygen atoms must be present on the catalyst surface for the complete combustion of one molecule of ethene. In the meantime, six molecules of ethene oxide will be formed. Therefore a maximum selectivity of $6 / 7=85.7 \%$ will be found if this mechanism is correct. In Refs. [2] and [9-16], a mechanism is suggested in which molecular oxygen is the active component for epoxidation. However, on the basis of theoretical considerations [3,17] and studies involving special techniques such as IR spectroscopy, temperature-programmed desorption (TPD) and temporal analysis of products (TAP) [7,18-21], and because the selectivities have been reported to be above $85.7 \%$ [16,22], mechanisms based on one single adsorbed state of atomic oxygen in both reactions are favoured. The bond in molecular oxygen is assumed to be broken by dissociative adsorption of oxygen on the catalyst surface.

It is generally believed that the rate-determining step is the surface reaction of adsorbed oxygen with ethene $[3,13]$. Although ethene is not adsorbed on clean silver, it is adsorbed on an oxygen covered silver surface. Rupture of the double bond of ethene by an electrophilic adsorbed atom or molecule of oxygen leads to the formation of ethene oxide. No consistent description is found in the literature for the mechanism of the total combustion reaction. Presumably, ethene adsorbs dissociatively on the catalyst surface, during which the bond between a hydrogen atom and a carbon atom is broken, which ultimately leads to the formation of carbon dioxide and water.

\subsection{Influence of reaction products}

The oxidation products, $\mathrm{CO}_{2}, \mathrm{H}_{2} \mathrm{O}$ and $\mathrm{EO}$, can have an influence on the catalyst. The role of each individual product, reported in the literature, will be discussed.

\subsubsection{Carbon dioxide}

In industry, reactors are run at high concentrations of carbon dioxide. Therefore research has been directed towards the influence of $\mathrm{CO}_{2}$ on the reaction rates, and little attention has been paid to $\mathrm{H}_{2} \mathrm{O}$ and $\mathrm{EO}$. Carbon dioxide can form carbonates reversibly on an oxidized silver surface $[18,19,23-25]$ according to

$$
\mathrm{CO}_{2}+\mathrm{O}(\mathrm{ads}) \rightleftharpoons \mathrm{CO}_{3} \text { (ads) }
$$

No influence of $\mathrm{CO}_{2}$ on the reaction rates was found in Ref. [26]. Later [2,27], the epoxidation reaction was observed to be inhibited by $\mathrm{CO}_{2}$, but the total combustion reaction was unaffected. In Refs. [22], [24], [28] and [29], the total combustion reaction was found to be inhibited. In Refs. [30] and [31], it was claimed that both reactions were inhibited, but this effect was stronger for the epoxidation reaction. A stronger inhibition for the total combustion reaction was reported in Refs. [4], [13], [18], [19], [21], [32] and [33]. Both reactions were claimed to be inhibited to the same extent in Ref. [7]. Most workers regard carbon dioxide to be the most inhibiting product. However, in Ref. [5], the influence of the reaction products was arranged in the following order of the strength of inhibition: $\mathrm{C}_{2} \mathrm{H}_{4} \mathrm{O}>\mathrm{H}_{2} \mathrm{O}>\mathrm{CO}_{2}$. 


\subsubsection{Water}

Water is thought to adsorb dissociatively on an oxidized silver surface to form surface hydroxides $[18,19,23,34]$ according to

$\mathrm{H}_{2} \mathrm{O}+\mathrm{O}(\mathrm{ads}) \rightleftharpoons 2 \mathrm{OH}(\mathrm{ads})$

In Ref. [27], almost no influence of water on the reaction rates was found, whereas in Refs. [13] and [26] it was claimed that product inhibition of the rates was mainly caused by water. In Ref. [32], only a small inhibition by water was observed, which was slightly stronger for epoxidation. An inhibition of epoxidation and promotion of complete combustion were found in Ref. [35]. In Refs. [4], [13] and [36], it was reported that the combustion reaction was inhibited to a larger extent than the epoxidation reaction.

\subsubsection{Ethene oxide}

The influence of ethene oxide on epoxidation and total combustion is difficult to determine when its concentration is not obtained independently. This is caused by the increasing rate of ethene oxide decomposition at higher ethene oxide partial pressures, which apparently leads to higher total combustion rates; the direct effect of ethene oxide on the rates of epoxidation and total combustion cannot be determined separately from the rate of combustion of ethene oxide.

During the first hours of addition of ethene oxide to the feed, an inhibition of the epoxidation rate was found in Ref. [32], whereas the total combustion reaction was hardly influenced. After this initial period, the conversion slowly decreased until no catalytic activity remained. In Ref. [2], an inhibition of the epoxidation rate was observed and a slightly higher combustion rate was obtained which was explained by the decomposition of ethene oxide. In Ref. [16], it was reported that both reaction rates were inhibited by the chemisorption of ethene oxide on the surface. A larger inhibition of epoxidation than total combustion was found in Refs. [4] and [5]. In contrast, in Refs. [18] and [19], a reduction in the reaction rates and an increase in selectivity was found. Table 1 summarizes the reported effects of the products on the reaction rates. The assignment to the different classes is somewhat arbitrary.

We observe that conflicting results are found regarding the effect of the reaction products on the reaction rates. To some extent, this can be attributed to the disguising effect of one product over the others $[15,37]$. The main reason for the contradictory conclusions is thought to be the different promoters on the catalyst surface $[20,22-24,35]$; in addition, the different supports, the presence of modifiers and the partial pressures of the reactants may be important, e.g. whether oxygen is present in excess or not.
Table 1

Influence of reaction products on the epoxidation and total combustion reactions as reported in the literature. Symbol on left-hand side refers to epoxidation and symbol on right-hand side to total combusion: + , rate increases; =, no effect; - , rate decreases; - - , rate decreases so strongly that selectivity is also affected

\begin{tabular}{|c|c|c|c|}
\hline \multirow[t]{2}{*}{ Reference } & \multicolumn{3}{|l|}{ Product } \\
\hline & $\mathrm{EO}$ & $\mathrm{CO}_{2}$ & $\mathrm{H}_{2} \mathrm{O}$ \\
\hline Murray [36] & & & $-1--$ \\
\hline Schultze and Thiele [26] & & $=1=$ & $--1--$ \\
\hline Hayes [27] & & $-1=$ & $=1=$ \\
\hline Nault et al. [30] & & $--1-$ & \\
\hline Mikami ct al. [28] & & $=1 \ldots$ & \\
\hline Metcalf and Harriot [32] & $--1=$ & $-1--$ & $-1-$ \\
\hline Force and Bell [19] & $-1--$ & $-1--$ & \\
\hline Temkin [5] & $--1-$ & & \\
\hline Bremer [13] & & $=1-$ & $-1--$ \\
\hline Griffe et al. [22] & & $=1-$ & \\
\hline Stoukides and Pavlou [2] & $-1+$ & $-1=$ & \\
\hline Al-Saleh et al. [31] & & $--1-$ & \\
\hline Hall and Neubauer [7] & & $-1-$ & \\
\hline Park and Gau [16] & & $-1-$ & \\
\hline Tan et al. [24] & & $=1--$ & \\
\hline Gleaves et al. [21] & & $-1--$ & \\
\hline Liu et al. [35] & & & $-1+$ \\
\hline Bulushev and Khasin [29] & & $=1-$ & \\
\hline Eliyas and Petrov [33] & & $-1--$ & \\
\hline Borman and Westerterp [4] & $--1-$ & $-1--$ & $-1--$ \\
\hline
\end{tabular}

\subsection{Kinetic model}

Four different kinetic models have been derived and are used to interpret the kinetic data. The reaction of ethene with adsorbed oxygen is considered to be the rate-determining step in all models. The reactants and products compete for adsorption on the same reactive sites. Thus product inhibition is accounted for by the decreased number of available active sites on the catalyst surface at high product concentrations in the gas phase. The epoxidation and total combustion reactions are thought to takc place on different sites. Differences in selectivity are caused by the preference of products to adsorb on a certain site which is only involved in one reaction. The models differ in the state of ethene and the type of oxygen involved in the reactions. Models 1 and 2 are Eley-Rideal kinetic models in which ethene reacts in the gas phase with adsorbed oxygen. Models 3 and 4 are Langmuir-Hinshelwood models in which ethene reacts in an adsorbed state. Models 1 and 3 consider atomic oxygen to be the active component on the catalyst surface, whereas in models 2 and 4 the active component is molecular oxygen. The mathematical representation of the different kinetic models for both reactions is as follows

$r_{i}=\frac{k_{\mathrm{r}}^{i} \sqrt{K_{\mathrm{O}}^{i}} P_{\mathrm{E}} \sqrt{P_{\mathrm{O}}}}{1+\sqrt{K_{\mathrm{O}}^{i} P_{\mathrm{O}}}+K_{\mathrm{C}}^{i} P_{\mathrm{C}}+K_{\mathrm{W}}^{i} P_{\mathrm{W}}+K_{\mathrm{EO}}^{i} P_{\mathrm{EO}}}$ 
$r_{i}=\frac{k_{\mathrm{r}}^{i} K_{\mathrm{O}}^{i} P_{\mathrm{E}} P_{\mathrm{O}}}{1+K_{\mathrm{O}}^{i} P_{\mathrm{O}}+K_{\mathrm{C}}^{i} P_{\mathrm{C}}+K_{\mathrm{W}}^{i} P_{\mathrm{W}}+K_{\mathrm{EO}}^{i} P_{\mathrm{EO}}}$

$r_{i}=\frac{k_{\mathrm{r}}^{i} K_{\mathrm{E}}^{i} \sqrt{K_{\mathrm{O}}^{i}} P_{\mathrm{E}} \sqrt{P_{\mathrm{O}}}}{\left(1+K_{\mathrm{E}}^{i} P_{\mathrm{E}}+\sqrt{K_{\mathrm{O}}^{i} P_{\mathrm{O}}}+K_{\mathrm{C}}^{i} P_{\mathrm{C}}+K_{\mathrm{W}}^{i} P_{\mathrm{W}}+K_{\mathrm{EO}}^{i} P_{\mathrm{EO}}\right)^{2}}$

$r_{i}=\frac{k_{\mathrm{r}}^{i} K_{\mathrm{E}}^{i} K_{\mathrm{O}}^{i} P_{\mathrm{E}} P_{\mathrm{O}}}{\left(1+K_{\mathrm{E}}^{i} P_{\mathrm{E}}+K_{\mathrm{O}}^{i} P_{\mathrm{O}}+K_{\mathrm{C}}^{i} P_{\mathrm{C}}+K_{\mathrm{W}}^{i} P_{\mathrm{W}}+K_{\mathrm{EO}}^{i} P_{\mathrm{EO}}\right)^{2}}$

For ethene epoxidation $i=1$ and for total combustion $i=2$. A distinctive site for each reaction is introduced implicitly in the models by giving the constants different values for $i=1$ and $i=2$. All components appear together in the denominator of the equations because only one site is available for them. The reaction and adsorption rate constants are assumed to be dependent on the temperature according to the Arrhenius law

$k_{\mathrm{r}}^{i}=k_{\mathrm{r}, \infty}^{i} \exp \left(-\frac{T_{\mathrm{act}}}{T}\right)$

$K_{j}^{i}=K_{j, \infty}^{i} \exp \left(\frac{T_{\text {ads }}}{T}\right)$

A kinetic model is a simplification of the phenomena occurring on the catalyst surface, and therefore kinetic rate expressions should be considered as semi-empirical equations which allow the reaction rates to be predicted under certain operating conditions with a certain accuracy. This is illustrated in Ref. [4] where it was found that the same kinetic data could be interpreted equally well with three different rate equations based on different mechanisms.

\section{Experimental details}

The reactions were carried out with ethene, an excess of air and without the addition of a chlorine modifier. An industrial silver on $\alpha$-alumina Raschig ring was used as catalyst. Because of confidentiality reasons, we are unable to provide more detailed information on the catalyst formulation. A laboratory recycle reactor with a design similar to that in Ref. [38] was used to determine the kinetics. In addition a new, improved recycle reactor was used, the Bobo reactor. The Bobo reactor has better mixing characteristics and much lower interparticle resistances than the Berty reactor [39]. A description of both reactors and details of the experiments can be found elsewhere [1,4]. A third series of experiments with products added to the reactor feed was performed in a tubular reactor with a bed length of $0.50 \mathrm{~m}$. This set-up has been discussed in detail in Ref. [40]. High purity carbon dioxide $(99.97 \%)$ and/or water vapour were added to the reactor feed. The amount of carbon dioxide added was controlled by a mass flow controller. Water vapour was added to the feed by saturating a side stream of the feed gas in a water vaporizer (see Fig. 2), whose temperature was controlled with an electrical heater. The water concentration in the feed was controlled by changing the temperature of the water in the saturator and the fraction of the feed flowing through it. The water content in the feed was measured with a chilled mirror dew point measuring device (Panametrics), with an accuracy in the dew point temperature of about 0.5 $\mathrm{K}$. The carbon dioxide and ethene concentrations in the gas were measured with a gas chromatograph and the $\mathrm{CO}_{2}$ concentration was also measured on-line with an IR spectrometer. The catalyst activity was checked regularly at standard conditions during the kinetic experiments. Deactivation was observed, and therefore it was decided to replace the catalyst as soon as the activity decreased to less than $90 \%$ of its original value. This had to be done twice in the two recycle reactors and once in the tubular reactor. A total of 130 experiments were performed in the Berty-type recycle reactor, 51 in the Bobo reactor and 79 in the tubular reactor. The temperature, total pressure and component partial pressure ranges in the kinetic experiments are given in Table 2. Ethene oxide was not added to the feed of the tubular reactor, because we failed to develop a reliable dosing system for this component.

\subsection{Data interpretation}

The results of the kinetic experiments in both recycle reactors were interpreted by assuming the reactors to be ideally mixed. For the interpretation of data from the tubular reactor, a differential technique was used [1]. The data were fitted with the SIMUSOLV ${ }^{\text {tn }}$ program to a number of possible reaction rate equations. This commercial, statistical software package allows values for the kinetic constants to be estimated and evaluated [41] on the basis of the optimization of a non-linear, multi-response model. The parameters were rescaled by

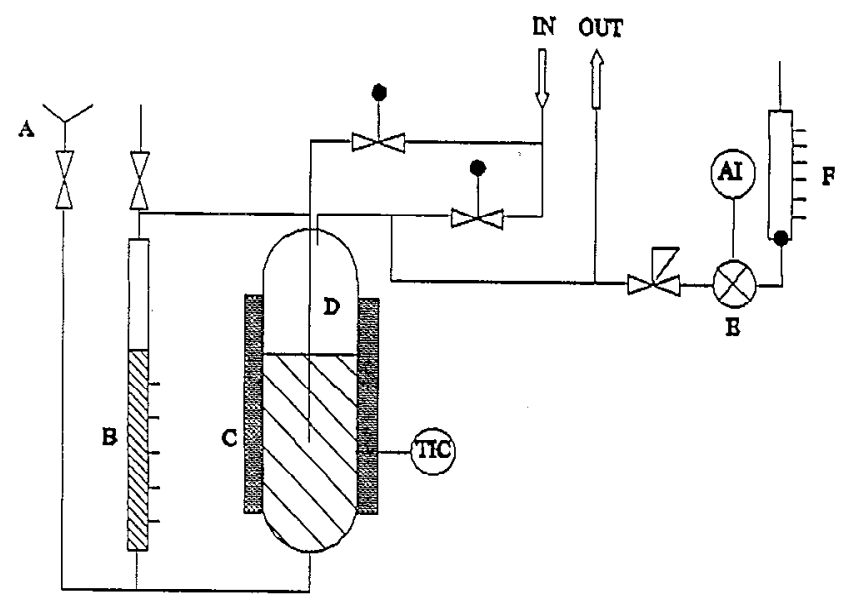

Fig. 2. Experimental set-up for the addition of water vapour to the feed: A, supply line; B, supply vessel; C, electrical heater; D, saturation vessel; $\mathrm{E}$, dew point measuring device; $\mathrm{F}$, flow controller. 
Table 2

Investigated range of parameters in the kinetic experiments

\begin{tabular}{llll}
\hline Parameter & Berty-type reactor & Bobo reactor & Cooled tubular reactor \\
\hline$T$ (K) & $455-528$ & $455-512$ & $434-496$ \\
$P$ (bar) & $1.8-10.0$ & $1.8-9.0$ & $2.0-10.0$ \\
$P_{\mathrm{E}}$ (mbar) & $3-177$ & $4-151$ & $4-101$ \\
$P_{\mathrm{O}}$ (bar) & $0.37-2.08$ & $0.37-1.86$ & $0.42-2.09$ \\
$P_{\mathrm{EO}}$ (mbar) & $5-58$ & $0.2-22$ & 0 \\
$P_{\mathrm{C}}$ (mbar) & $1-79$ & $0.4-21$ & $0-25$ \\
$P_{\mathrm{W}}$ (mbar) & $1-63$ & $0.4-21$ & $0-47$ \\
\hline
\end{tabular}

introducing a reference temperature and by taking the logarithm of the pre-exponential constants [4]. The accuracy of the final result depends on the starting values for the kinetic constants. Good starting values for each kinetic constant were obtained by avoiding systematic deviations in small data sets in which the relevant parameter is varied while the other parameters are kept more or less constant. The effect of the addition of products to the feed on the behaviour of a wall-cooled, packed-bed reactor was studied theoretically by simulations with a two-dimensional heterogeneous model in which the kinetic expressions obtained were incorporated. Details concerning the model and the description of heat transport are given in Ref. [40].

\section{Results and discussion}

The kinetic constants of Eq. (1) for all four models were determined by fitting the three data sets separately and also all data simultaneously. It was not possible to obtain statistically reliable values for all kinetic constants because strong cross- correlations exist, e.g. between the adsorption energies and the corresponding pre-exponential adsorption constants. These cross- correlations were so strong that it was better to take a constant value than an Arrhenius-type function. The adsorption constants for ethene were an exccption: the introduction of an adsorption energy for ethene resulted in a significantly better fit. Thus the temperature dependence of all adsorption constants was neglected except for ethene chemisorption. The fitted kinetic constants are listed in Table 3. At the end of this section it will be shown that all adsorption constants are relevant.

\subsection{Model discrimination}

The choice between different models was based, in principle, on the difference in the average errors. The average error of a data set fitted to a model is defined as follows

$f=\frac{1}{N} \sum_{i=1}^{N} \frac{\left|R_{\mathrm{exp}, i}-R_{\mathrm{calc}, i}\right|}{R_{\mathrm{exp}, i}}$
The average errors for each data set are given in Table 3 for the epoxidation and total combustion reactions. The experimental data are compared with the calculated values in parity plots in Fig. 3. Systematic deviations can be observed in some of the parity plots. We studied the systematic deviations by plotting the relative distribution of errors $S_{i}$ as a function of an independent variable, where

$S_{i}=\frac{R_{\mathrm{exp}, i}-R_{\mathrm{calc}, i}}{R_{\mathrm{exp}, i}}$

The independent variable can be any parameter, such as the temperature, partial pressure of a particular component, flow rate, etc. No systematic deviations should be present in the residual graphs.

Models 1 and 2 were tested only for data from the Berty reactor because the results were unsatisfactory. Not only were larger average errors found compared with models 3 and 4, but also a systematic deviation at higher partial pressures of ethene. This is shown for model 2 in Fig. 4. The deviations are probably caused by the first order in ethene partial pressure for EleyRideal models. This will result in calculated reaction rates at increasing ethene partial pressures which are too high if the true order is lower than unity. The average errors do not allow discrimination between models 3 and 4 because they are about equal for all data sets. In Table 4, the surface coverages are shown, calculated using models 3 and 4 fitted to all the data, on the basis of the concentrations and temperatures measured in one experiment in the cooled tubular reactor. The conditions are given in Table 5. The oxygen surface coverage is high and varies considerably. Therefore a systematic deviation may possibly bc found for the oxygen partial pressure in view of the different influence of oxygen in the two models: in model 3, the square of the oxygen partial pressure is taken, whereas in model 4 , the oxygen partial pressure is raised to the power unity. In the residual graphs for oxygen, it is shown that no such deviations are present (see Fig. 5). Therefore it is not possible to discriminate between the two models on the basis of our experiments, and we have arbitrarily chosen model 4 to use in our studies of the cooled tubular reactor. 
Table 3

Kinetic constants obtained by fitting: (a) Berty reactor data set; (b) Bobo reactor data set; (c) tubular reactor data set; (d) all kinetic data (a) Berty data

\begin{tabular}{|c|c|c|c|c|c|c|c|c|}
\hline \multirow[t]{2}{*}{ Parameter } & \multicolumn{2}{|l|}{ Model 1} & \multicolumn{2}{|l|}{ Model 2} & \multicolumn{2}{|l|}{ Model 3} & \multicolumn{2}{|l|}{ Model 4} \\
\hline & $r_{1}$ & $r_{2}$ & $r_{1}$ & $r_{2}$ & $r_{1}$ & $r_{2}$ & $r_{1}$ & $r_{2}$ \\
\hline$k_{\mathrm{r}, \infty}$ & $35 \times 10^{3}$ & $1.49 \times 10^{3}$ & $16 \times 10^{3}$ & $0.55 \times 10^{6}$ & $0.97 \times 10^{6}$ & $30.4 \times 10^{6}$ & $0.50 \times 10^{6}$ & $7.34 \times 10^{0}$ \\
\hline$T_{\text {act }}$ & $5.9 \times 10^{3}$ & $8.7 \times 10^{3}$ & $5.9 \times 10^{3}$ & $8.7 \times 10^{3}$ & $9.5 \times 10^{3}$ & $11.2 \times 10^{3}$ & $9.2 \times 10^{3}$ & $10.7 \times 10^{3}$ \\
\hline$K_{\mathrm{E}, \infty}$ & - & - & - & - & 0.0122 & 0.144 & 0.0130 & 0.222 \\
\hline$T_{\text {uds,E }}^{L, \infty}$ & - & - & - & - & $3.5 \times 10^{3}$ & $2.4 \times 10^{3}$ & $3.5 \times 10^{3}$ & $2.5 \times 10^{3}$ \\
\hline$K_{0, \infty}$ & 61.7 & 35.5 & 20.6 & 24.0 & 35.2 & 5.9 & 5.8 & 4.9 \\
\hline $\mathrm{K}_{\mathrm{EO}, \infty}$ & $1.9 \times 10^{3}$ & $5.2 \times 10^{3}$ & $2.2 \times 10^{3}$ & $5.4 \times 10^{3}$ & 15 & 77 & 10 & 93 \\
\hline $\mathrm{K}_{\mathrm{C}, \infty}$ & $1.2 \times 10^{3}$ & 78 & $1.4 \times 10^{3}$ & 77 & 98 & 64 & 101 & 55 \\
\hline $\mathrm{K}_{\mathrm{w}}$ & $1.0 \times 10^{3}$ & 78 & $1.2 \times 10^{3}$ & 78 & 55 & 8 & 55 & 14 \\
\hline$f(\%)$ & 25.8 & 32.4 & 29.6 & 33.8 & 13.0 & 10.8 & 12.8 & 11.0 \\
\hline
\end{tabular}

(b) Bobo data

\begin{tabular}{llllll}
\hline Parameter & \multicolumn{2}{l}{ Model 3} & \multicolumn{3}{l}{ Model 4} \\
\cline { 2 - 3 } \cline { 5 - 6 } & $r_{1}$ & $r_{2}$ & & $r_{1}$ & $r_{2}$ \\
\hline$k_{\mathrm{r}, \infty}$ & $0.49 \times 10^{6}$ & $1.24 \times 10^{9}$ & $0.48 \times 10^{6}$ & $1.32 \times 10^{9}$ \\
$T_{\text {act }}$ & $9.1 \times 10^{3}$ & $1.27 \times 10^{3}$ & $9.1 \times 10^{3}$ & $12.7 \times 10^{3}$ \\
$K_{\mathrm{E}, \infty}$ & 0.026 & 0.018 & & 0.026 & 0.018 \\
$T_{\mathrm{ads}, \mathrm{E}}$ & $3.2 \times 10^{3}$ & $3.5 \times 10^{3}$ & & $3.2 \times 10^{3}$ & $3.5 \times 10^{3}$ \\
$K_{\mathrm{O}, \infty}$ & 20.9 & 5.0 & 4.6 & 6.0 \\
$K_{\mathrm{EO}, \infty}$ & 9 & 58 & 9 & 62 \\
$K_{\mathrm{C}, \infty}$ & $0.15 \times 10^{3}$ & $0.20 \times 10^{3}$ & $0.13 \times 10^{3}$ & $0.29 \times 10^{3}$ \\
$K_{\mathrm{W}}$ & 41 & $0.13 \times 10^{3}$ & 40 & $0.16 \times 10^{3}$ \\
$f(\%)$ & 13.3 & 12.0 & 11.8 & 9.4 \\
\hline
\end{tabular}

(c) Tubular reactor

\begin{tabular}{|c|c|c|c|c|}
\hline \multirow[t]{2}{*}{ Parameter } & \multicolumn{2}{|l|}{ Model 3} & \multicolumn{2}{|l|}{ Model 4} \\
\hline & $r_{1}$ & $r_{2}$ & $r_{1}$ & $r_{2}$ \\
\hline$k_{r, \infty}$ & $0.76 \times 10^{6}$ & $10.5 \times 10^{9}$ & $0.92 \times 10^{6}$ & $16.1 \times 10^{9}$ \\
\hline$T_{\text {act }}$ & $8.8 \times 10^{3}$ & $12.8 \times 10^{3}$ & $8.8 \times 10^{3}$ & $12.6 \times 10^{3}$ \\
\hline$K_{\mathrm{E}, \infty}$ & 0.010 & 0.0021 & $9.6 \times 10^{-3}$ & $1.6 \times 10^{-3}$ \\
\hline$T_{\mathrm{ads}, \mathrm{E}}$ & $3.0 \times 10^{3}$ & $3.5 \times 10^{3}$ & $3.0 \times 10^{3}$ & $3.4 \times 10^{3}$ \\
\hline$K_{\mathrm{O}, \infty}$ & 2.2 & 10.4 & 1.5 & 3.2 \\
\hline$K_{\mathrm{EO}, \infty}$ & - & - & - & - \\
\hline$K_{\mathrm{C}, \infty}$ & 24 & 89 & 27 & 96 \\
\hline$K_{\mathrm{W}}$ & 50 & 40 & 50 & 43 \\
\hline$f(\%)$ & 27.0 & 24.2 & 27.7 & 25.1 \\
\hline
\end{tabular}

(d) All data

\begin{tabular}{|c|c|c|c|c|}
\hline \multirow[t]{2}{*}{ Parameter } & \multicolumn{2}{|l|}{ Model 3} & \multicolumn{2}{|l|}{ Model 4} \\
\hline & $r_{1}$ & $r_{2}$ & $r_{1}$ & $r_{2}$ \\
\hline$k_{r, \infty}$ & $0.695 \times 10^{6}$ & $0.15 \times 10^{9}$ & $36.5 \times 10^{6}$ & $0.316 \times 10^{9}$ \\
\hline$T_{\text {act }}$ & $9.0 \times 10^{3}$ & $11.4 \times 10^{3}$ & $8.8 \times 10^{3}$ & $12.8 \times 10^{3}$ \\
\hline$K_{\mathrm{E}, \infty}$ & 0.012 & 0.14 & 0.022 & 0.0065 \\
\hline$T_{\tilde{a} \mathrm{ds}, \mathrm{E}}$ & $3.1 \times 10^{3}$ & $2.3 \times 10^{3}$ & $3.0 \times 10^{3}$ & $3.6 \times 10^{3}$ \\
\hline$K_{\mathrm{O}, \infty}$ & 8.8 & 14.9 & 1.5 & 3.0 \\
\hline$K_{\mathrm{EO}, \infty}$ & 88 & $0.38 \times 10^{3}$ & $0.10 \times 10^{3}$ & $0.25 \times 10^{3}$ \\
\hline$K_{\mathrm{C}, \infty}$ & 75 & $0.13 \times 10^{3}$ & 60 & $0.13 \times 10^{3}$ \\
\hline$K_{\mathrm{W}}$ & 63 & 28 & 40 & 55 \\
\hline$f(\%)$ & 25.4 & 24.4 & 25.2 & 23.9 \\
\hline
\end{tabular}

\subsection{Different data sets}

In Table 3, it is shown that the combustion reaction is slightly, but systematically, better described by the reaction rate expressions than is the epoxidation reaction. The difference in average error between the two reactions may be explained by the fact that the production rates of total combustion are obtained directly from the experimentally determined concentrations, whereas the ethene oxide concentration has not been measured but must be calculated from the difference between the amount of ethene converted and the carbon dioxide produced. Thus the determination of the ethene oxide concentration becomes less accurate: con- centrations of ethene and carbon dioxide are measured with an accuracy of about $3 \%$, which gives an inaccuracy in the ethene oxide concentrations of around $9 \%$.

The average errors of fitting for the Berty and Bobo reactor data are much smaller than the average error of fitting for the tubular reactor data set. This may be explained by the inaccuracy of the method used to obtain the latter data set from the experiments: apparently the determination of the slope of the temperature and the conversion profile at the inlet is not accurate. One explanation may be that the second-order polynomial equations derived from the first three axial points do not fit the profile accurately. A different explanation may be that the method becomes inaccurate if radial temperature profiles are significant [1]. 

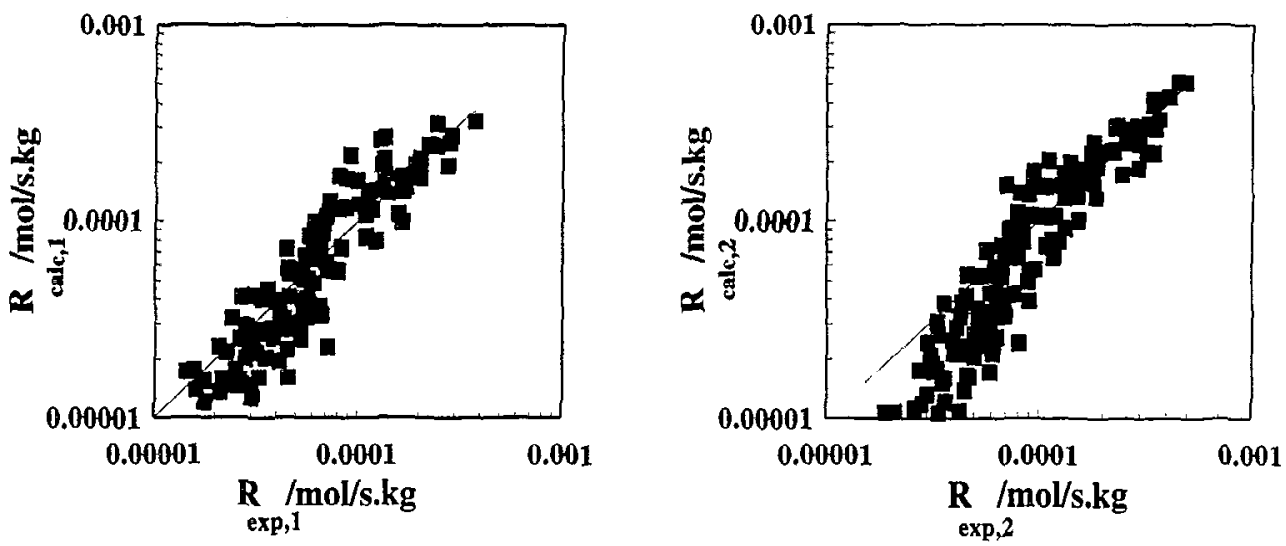

Ia

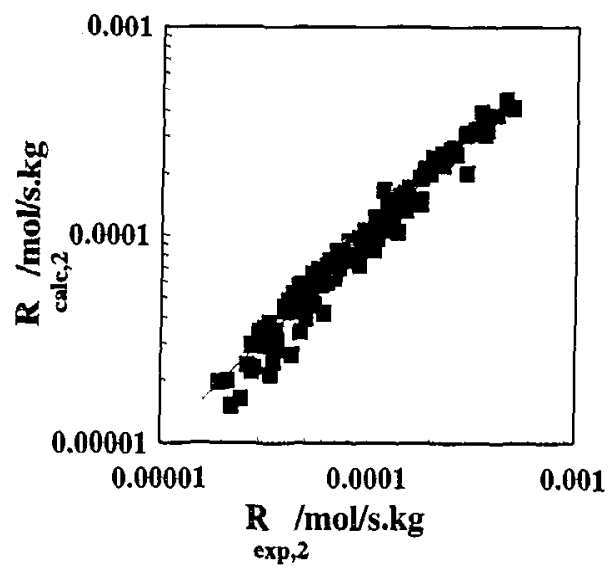

II a

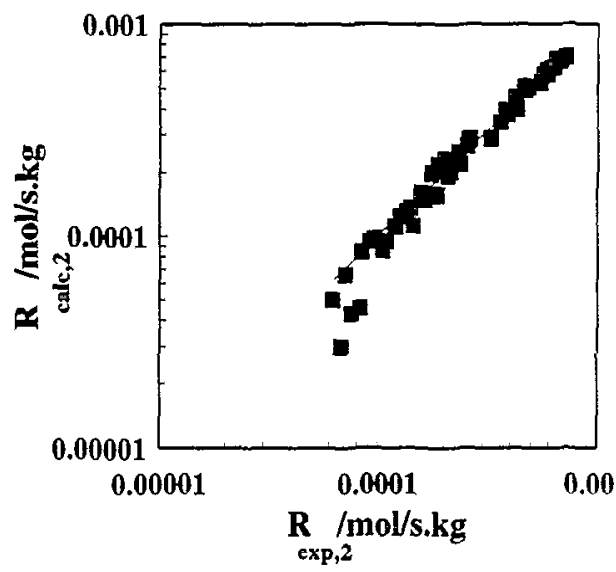

II b

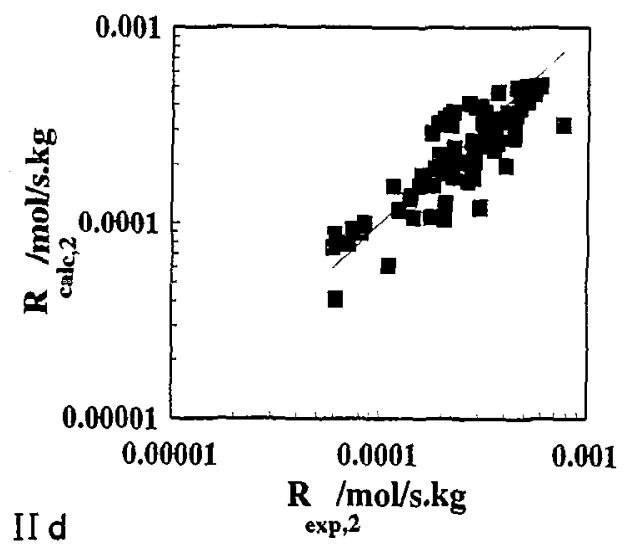

II C
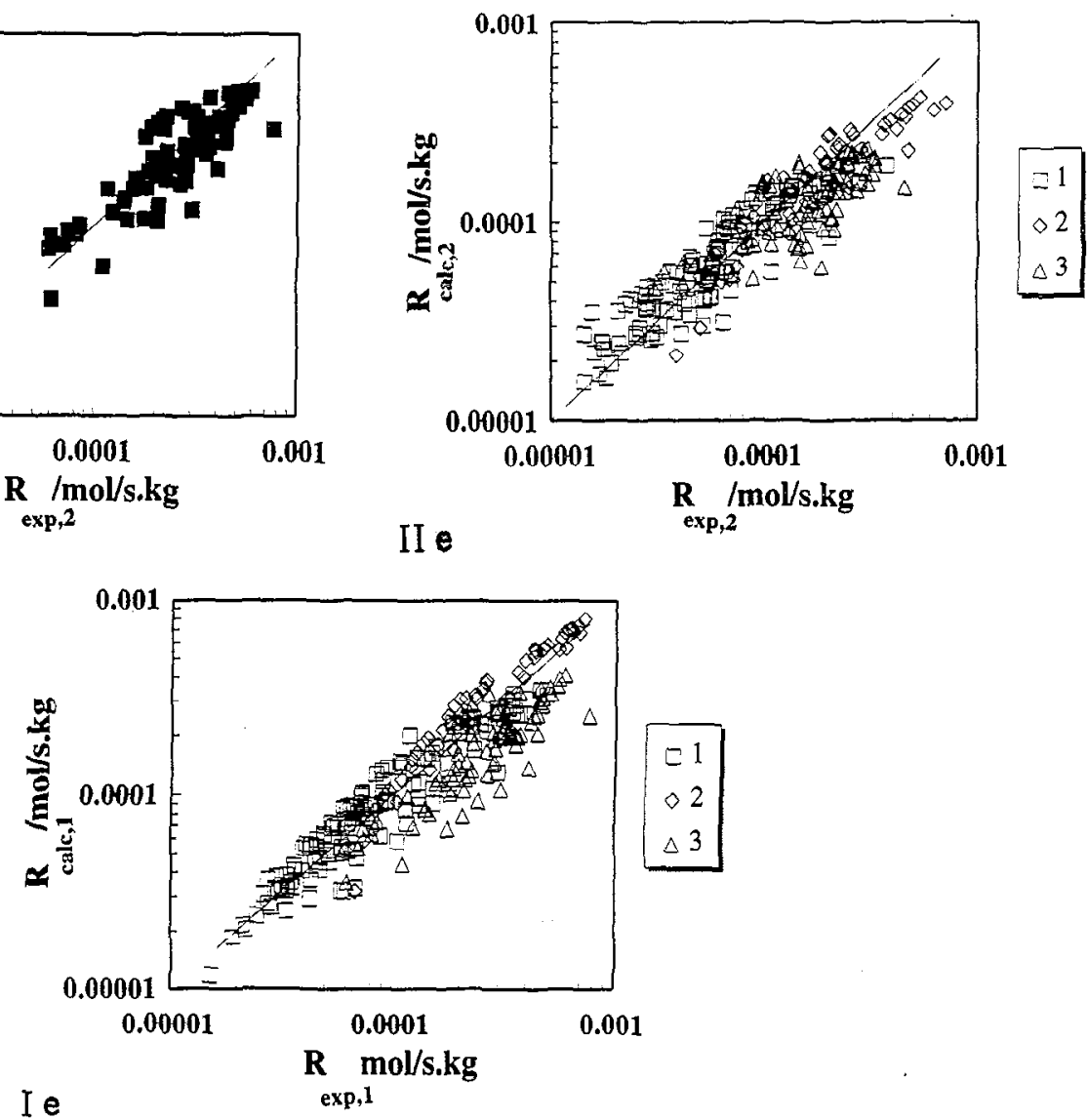

Fig. 3. Comparison of the experimental and calculated reaction rates of the epoxidation reaction (I) and the total combustion reaction (II) for the Berty data sef fitted to model 2 (a) and model 3 (b), the Bobo data set fitted to model 4 (c), the tubular reactor data set fitted to model 3 (d) and all kinetic data fitted to model 4 (e); 1, Berty reactor data; 2, Bobo reactor data; 3 , tubular reactor data. 

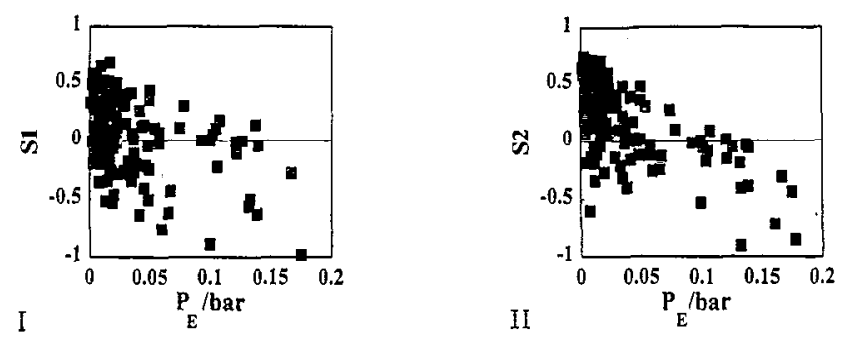

Fig. 4. Relative distribution of errors of the epoxidation (I) and total combustion (II) reactions vs. the partial pressure of ethene for the Berty reactor data set fitted to model 2.

Fitting of the three different data sets separately and of all data simultaneously leads to different kinetic constants. The resulting reaction rates are compared for three arbitrary sets of conditions in Table 5, which correspond to one certain profile in the cooled tubular reactor. The four reaction rate expressions predict different rates in each case. The discrepancies may be explained to some extent by a possible error introduced by the extrapolation of the reaction rate expressions outside their experimental data range. The expressions based on Berty and Bobo reactor data are extrapolated to conditions of zero product concentration, but it is not possible to operate a recycle reactor at such conditions. The experimental data in the tubular reactor were obtained with one product added at a time and have been extrapolated to conditions at which all products are present simultaneously. Furthermore, the experimental data sets may deviate because of poisoning [1]. Poisoning may lead to deactivation of the catalyst during the experiments and to different catalyst activities towards the two reactions. In the latter case, different reaction rate expressions will be obtained if data from each reactor are fitted individually. In addition, inconsistent results will be obtained if all data are fitted simultaneously. We can look for such inconsistencies in the residual graphs of the fit of all the data (see Fig. 6). Distinctive systematic deviations are found for residuals vs. an arbitrary product partial pressure. Attempts to eliminate these deviations by changing the adsorption constants of the products were unsuccessful, and there-

Table 4

Range of surface coverages based on experiments of Schouten et al. [40] and calculations with rate expressions based on the total data set and models 3 and 4

\begin{tabular}{lcccrc}
\hline & \multicolumn{3}{c}{ Model 3 } & & \multicolumn{2}{c}{ Model 4 } \\
\cline { 2 - 3 } \cline { 5 - 6 } & \multicolumn{1}{c}{$r_{1}$} & $r_{2}$ & & $r_{1}$ & \multicolumn{1}{c}{$r_{2}$} \\
\hline Ethene (\%) & $2-8$ & $3-11$ & & $4-13$ & $2-9$ \\
Oxygen (\%) & $47-74$ & $38-75$ & & $31-63$ & $38-77$ \\
Ethene oxide (\%) & $0-18$ & $0-32$ & & $0-17$ & $0-23$ \\
Carbon dioxide (\%) & $0-15$ & $0-16$ & & $0-15$ & $0-17$ \\
Water (\%) & $0-12$ & $0-3$ & & $0-10$ & $0-7$ \\
Empty (\%) & $11-29$ & $8-24$ & $15-48$ & $8-34$ \\
\hline
\end{tabular}

Table 5

Reaction rates calculated for three different conditions with four different reaction rate expressions for the epoxidation and total combustion reactions

\begin{tabular}{llll}
\hline Parameter & Case A & Case B & Case C \\
\hline$T$ (K) & 465.5 & 501.0 & 476.2 \\
$P_{\mathrm{E}}$ (mbar) & 35.8 & 30.3 & 23.2 \\
$P_{\mathrm{O}}$ (bar) & 1.05 & 1.03 & 1.01 \\
$P_{\mathrm{EO}}$ (mbar) & 0 & 3.3 & 6.5 \\
$P_{\mathrm{C}}$ (mbar) & 0 & 4.6 & 12.5 \\
$P_{\mathrm{H}}$ (mbar) & 0 & 4.6 & 12.5 \\
$r_{1}{ }^{\mathrm{a}}$ & $0.104 \times 10^{-3}$ & $0.201 \times 10^{-3}$ & $0.064 \times 10^{-3}$ \\
$r_{2}{ }^{\mathrm{a}}$ & $0.110 \times 10^{-3}$ & $0.334 \times 10^{-3}$ & $0.089 \times 10^{-3}$ \\
$r_{1}{ }^{\mathrm{b}}$ & $0.145 \times 10^{-3}$ & $0.275 \times 10^{-3}$ & $0.080 \times 10^{-3}$ \\
$r_{2}{ }^{\mathrm{b}}$ & $0.185 \times 10^{-3}$ & $0.456 \times 10^{-3}$ & $0.070 \times 10^{-3}$ \\
$r_{1}{ }^{\mathrm{c}}$ & $0.264 \times 10^{-3}$ & $0.452 \times 10^{-3}$ & $0.131 \times 10^{-3}$ \\
$r_{2}{ }^{\mathrm{c}}$ & $0.423 \times 10^{-3}$ & $1.145 \times 10^{-3}$ & $0.227 \times 10^{-3}$ \\
$r_{1}{ }^{\mathrm{d}}$ & $0.190 \times 10^{-3}$ & $0.277 \times 10^{-3}$ & $0.067 \times 10^{-3}$ \\
$r_{2}{ }^{\mathrm{d}}$ & $0.278 \times 10^{-3}$ & $0.561 \times 10^{-3}$ & $0.086 \times 10^{-3}$ \\
\hline
\end{tabular}

"Berty data. ${ }^{\text {bBobo data. }}{ }^{\text {TTubular data. }}{ }^{\text {A All data. }}$

fore we assume that different catalyst behaviour in each reactor may be an important reason for the variations in the rates obtained. Differences in the catalyst behaviour may also explain why some of the kinetic constants, obtained by fitting to the total data set, have strongly deviating values compared with those obtained in separate studies. An example is the large values obtained for the ethene oxide adsorption constants. The reaction rates calculated from data in the tubular reactor are not influenced by this constant, because no ethene oxide was present in the feed during these experiments. However, in the Berty and Bobo reactors, ethene oxide is present, and the calculated reaction rates will decrease if the ethene oxide adsorption constant is increased. Thus it is possible that, when all data are fitted simultaneously, the lower measured reaction rates in the Berty and Bobo reactors compared with the tubular reactor cause the adsorption constant of ethene oxide to become excessively high. In this way, the effect of the difference in the catalyst activity between the reactors may become apparent in the kinetic constants.

We have chosen the reaction rate expressions obtained by fitting to all the data simultaneously, because we hope that these expressions will be valid for a broad range of operating conditions. Fitting to Berty and Bobo reactor data will possibly give a smaller error, but will yield rate expressions which are not applicable over the entire operating regime. A similar case has been reported in Ref. [42] in which data from recycle reactors were found to be misleading in extrapolating rate expressions for a parallel reaction scheme. Therefore kinetic experiments were conducted in an isothermal integral reactor. It should be realized that when fitting is done with more than one data set, differences in catalyst activity in the different series will become apparent in the derived kinetics. 

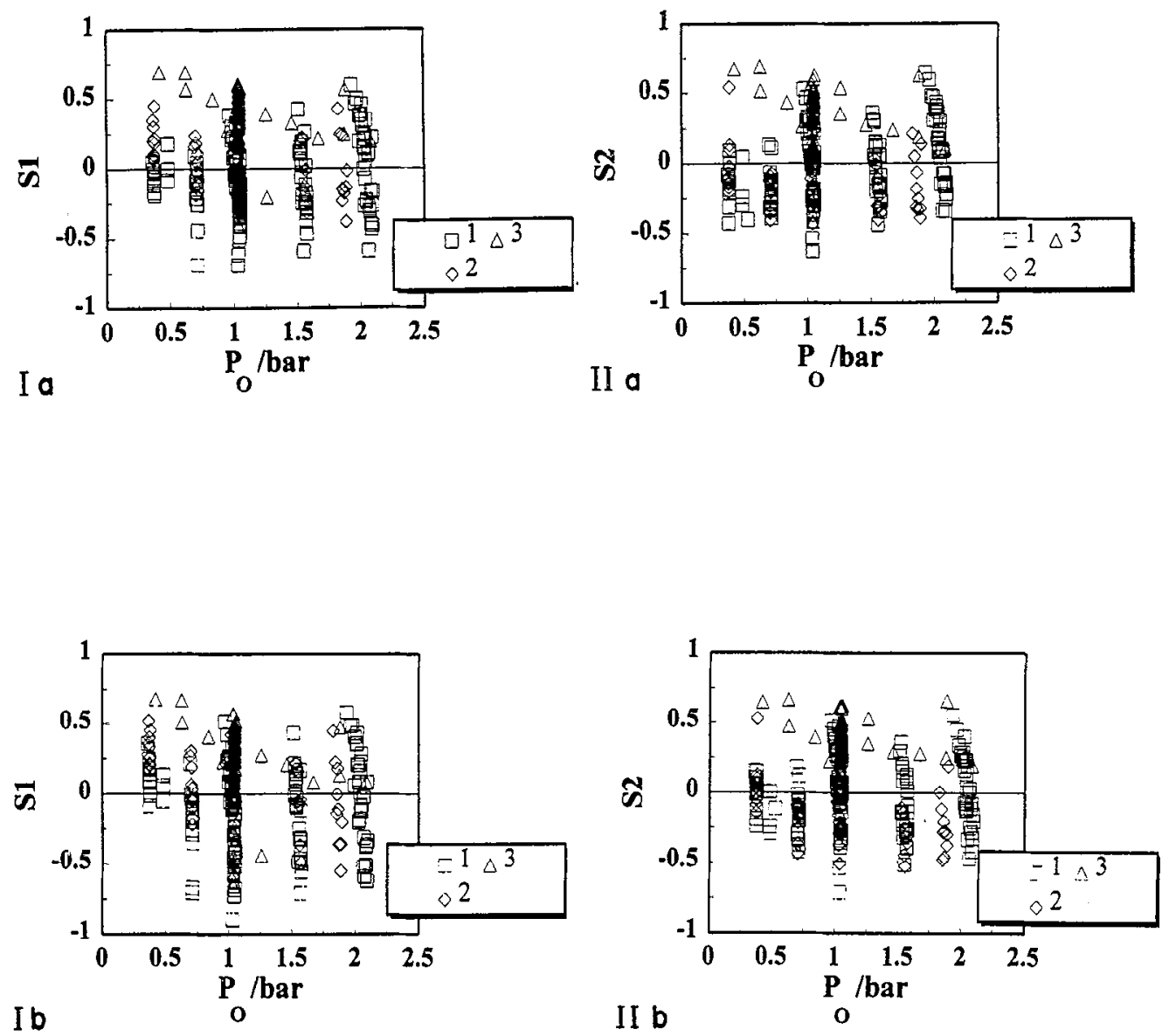

Fig. 5. Relative distribution of errors of the epoxidation (I) and total combustion (II) reactions vs. the oxygen partial pressure for all kinetic data fitted to model 3 (a) and to model 4 (b); 1, Berty reactor data; 2, Bobo reactor data; 3, tubular reactor data.

\subsection{Kinetic model}

In this section, some of the kinetic constants of the chosen model will be discussed. The apparent activation temperatures can be defined as $T_{\text {act }}-T_{\text {ads, }}$ because the surface coverage with ethene is near zero, which results in a negligible temperature dependence of the denominator of the rate expressions. Thus the apparent activation energies for the two reactions are $48.1 \mathrm{~kJ} \mathrm{~mol}^{-1}$ and $76.5 \mathrm{~kJ} \mathrm{~mol}^{-1}$ respectively. These values are in reasonable agreement with literature data [3]. The adsorption constants were obtained for all products. To show the influence of each particular product, we have set the corresponding adsorption constant to zero and calculated the reaction rate with the modified rate expression. The calculated reaction rate will be larger than the rate calculated with the unmodified rate expression, since the inhibition by that particular product will be neglected. The difference between the rates is a measure of the influence of the product under consideration and is given in Table 6 for the conditions in Table 5. All adsorption constants are relevant and the inhibition of the reaction rates is different for the two reactions. The influence of ethene oxide is largest and the selectivity increases for higher ethene oxide concentrations. Carbon dioxide also enhances the selectivity and inhibits the reactions somewhat less than ethene oxide. Water is found to decrease the selectivity only slightly, and its inhibiting effect is the smallest of the three reaction products.

\subsection{Influence of the addition of products}

The inhibition of the reaction rates by the reaction products was studied further by the addition of products to the feed of the tubular reactor. The conversion rate over the catalyst bed at constant operating conditions will decrease under the influence of inhibition. Furthermore, the selectivity will change because the chemisorption constants are different for the two reactions. In Table 7 , an example of the change in the experimentally measured conversions and selectivities on addition of carbon dioxide and/or water is shown. In Fig. 7, the temperature profiles are shown for the same experiments as listed in Table 7 . The lines through the experimental points were drawn using a spline technique. The effect of the addition of carbon dioxide is much larger than the influence of addition of water. The measured effect of each individual component is discussed below and is compared with calculations using the model. The results of these calculations should be treated with caution if they are compared with the 


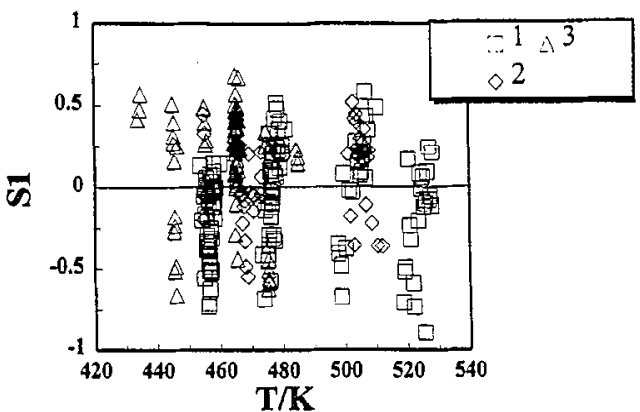

I a
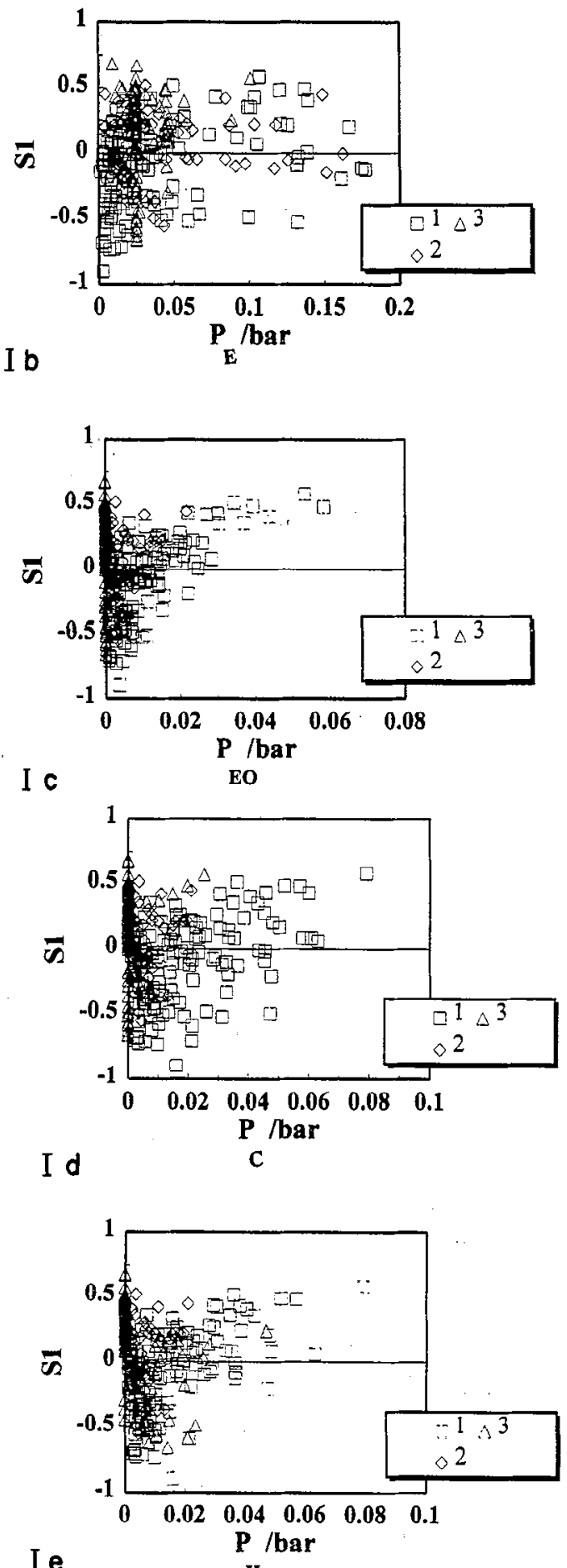

I e
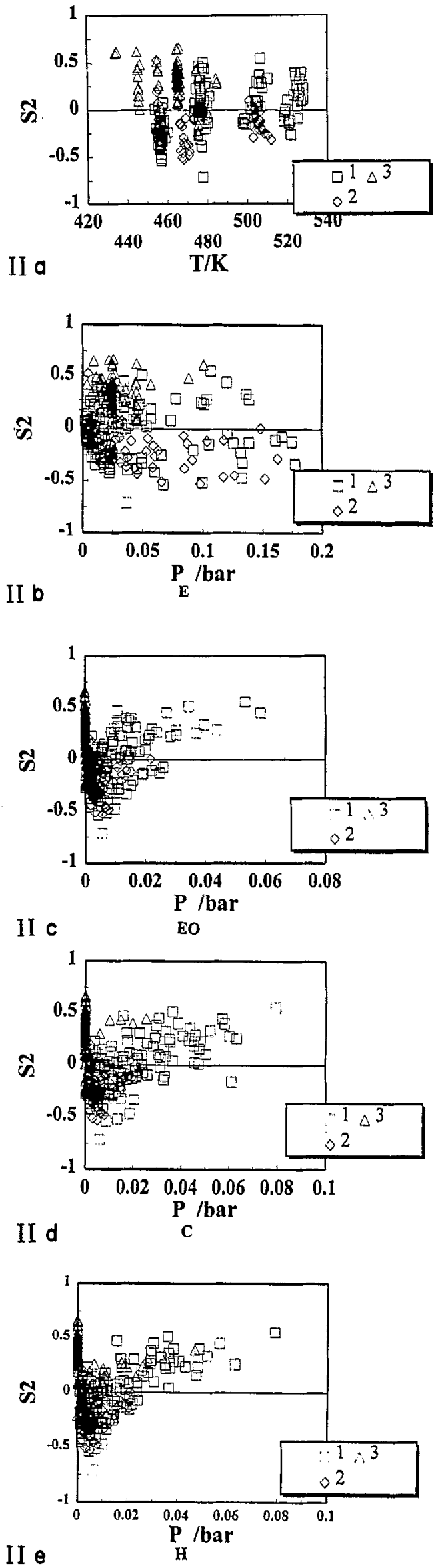

Fig. 6. Relative distribution of errors of the epoxidation (I) and total combustion (II) reactions vs. the temperature (a) and partial pressures of ethene (b), $\mathrm{EO}(\mathrm{c}), \mathrm{CO}_{2}$ (d) and $\mathrm{H}_{2} \mathrm{O}(\mathrm{e})$ based on all data and model 4. 
Table 6

Decrease in reaction rates in per cent by product inhibition under three conditions for the epoxidation and total combustion reactions (see Table 5 for conditions)

\begin{tabular}{llll}
\hline Condition & $\mathrm{EO}(\%)$ & $\mathrm{CO}_{2}(\%)$ & $\mathrm{H}_{2} \mathrm{O}(\%)$ \\
\hline$r_{1}:$ case A & 0 & 0 & 0 \\
$r_{2}:$ case A & 0 & 0 & 0 \\
$r_{1}:$ case B & 17.6 & 14.8 & 10.1 \\
$r_{2}:$ case B & 25.7 & 19.0 & 8.3 \\
$r_{1}:$ case C & 26.4 & 29.5 & 20.2 \\
$r_{2}:$ case C & 35.3 & 35.3 & 15.7 \\
\hline
\end{tabular}

experimental results in view of the inaccuracy and systematic deviations in the kinetic expressions. Therefore the sensitivity of the simulations to the kinetics is also discussed.

\subsubsection{Carbon dioxide}

In Fig. 8, the effect of carbon dioxide on the conversion, selectivity and axial temperature profile is demonstrated. Carbon dioxide is found to inhibit the reaction rates and to enhance the selectivity. Although the calculated conversions and selectivities are higher than the experimental values, the trends are predicted reasonably well. With regard to the axial temperature profiles, the experimental and calculated slopes at the reactor inlet decrease with increasing $\mathrm{CO}_{2}$ concentrations in the feed. The correspondence between the experimental and calculated temperature profiles is less satisfactory and some systematic deviations are found, in particular at the end of the reactor. This is probably caused by the systematic deviations in the kinetic equations discussed previously.

\subsubsection{Water}

In Fig. 9(a), the influence of water on the selectivity and conversion is shown. Water reduces both the selectivity and conversion only slightly. The trends in model calculations and experiments are the same: the conversion decreases at high water concentrations and the selectivity remains more or less the same. In Fig. 9(b), the axial temperature profiles are shown. The results are similar to those found for the addition of carbon

Table 7

Infiuence of the addition of carbon dioxide and water to the feed on the performance of the cooled tubular reactor. Conditions: $T_{\mathrm{w}}=465.8 \mathrm{~K}, \phi_{\mathrm{m}}=0.82 \mathrm{~kg} \mathrm{~m}^{-2} \mathrm{~s}^{-1}, P=0.50 \mathrm{MPa}$ and $x_{\mathrm{E}, \mathrm{in}}=0.91$ mol. $\%$

\begin{tabular}{llll}
\hline Experiment & Addition & $\zeta$ & $\sigma$ \\
\hline 1 & - & 0.444 & 0.575 \\
2 & $0.2 \% \mathrm{H}_{2} \mathrm{O}$ & 0.381 & 0.575 \\
3 & $0.1 \% \mathrm{CO}_{2}$ & 0.338 & 0.606 \\
4 & $0.1 \% \mathrm{CO}_{2}+0.2 \% \mathrm{H}_{2} \mathrm{O}$ & 0.283 & 0.545 \\
\hline
\end{tabular}

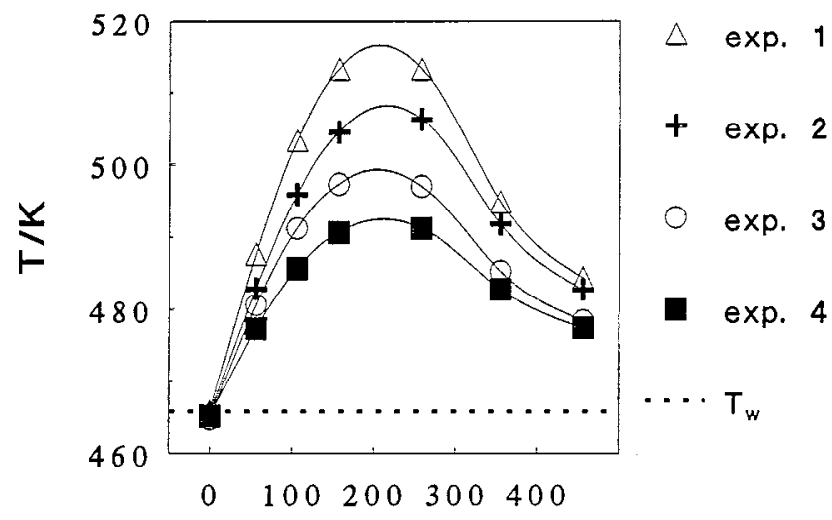

axial position $/ \mathrm{mm}$

Fig. 7. Influence of addition of $\mathrm{CO}_{2}$ and/or $\mathrm{H}_{2} \mathrm{O}$ to the feed of a cooled tubular reactor on the measured axial temperature profiles of the catalyst in the centre of the tube (see also Table 7).

dioxide. The observed influence of water is weaker than that of carbon dioxide.

\subsection{Sensitivity of calculated profiles to kinetics}

The rate expressions of the two reactions were multiplied with factors of 0.75 and 1.25 respectively to study the influence of kinetics on the calculated profiles; a deviation of $25 \%$ corresponds to the average error of the derived kinetic rate expressions. The results of the simulations of the cooled tubular reactor for the different cases are shown in Fig. 10 and Table 8. The kinetics have a large effect on both the calculated axial temperature profiles and the conversions. An increase of $25 \%$ in the reaction rates leads to an improved prediction of the experimental temperature profile. A decrease of $25 \%$ leads to calculated conversions and selectivities comparable with experimental values. As the two effects are opposite, a change in the absolute value of the reaction rates will not lead to a better description. Also changes in the heat transport parameters of the model do not give a more pronounced axial temperature profile, but the conversion is changed. It is necessary to increase the absolute values of the reaction rates and to decrease the heat transport parameters in the model to obtain a better correspondence. A rate expression based on a different mechanism may account for simultaneous changes in the right direction.

\section{Conclusions}

A Langmuir-Hinshelwood mechanism was chosen for both the epoxidation and total combustion reactions, because it was found necessary to include an adsorption term for ethene in the reaction rate expressions to obtain an order in ethene smaller than unity at high ethene partial pressures. It is difficult to discrimi- 
nate between a model with dissociated oxygen atoms and a model with adsorbed molecular oxygen on the basis of the experimental data, because the data sets are equally well described by the two models. We have arbitrarily chosen model 4 with molecular oxygen in our studies.

The separate data sets are described reasonably well by the individually fitted kinetic rate expressions, with a much larger average error for the data set from the tubular reactor. The main reason for this is the uncertainty of the method chosen to interpret the data obtained in the tubular reactor. The reaction rate expressions obtained for each individual data set differ considerably. We have chosen to fit the kinetic rate expressions to the data of all three sets in order to cover the entire operating regime of later experiments in a pilot plant. The final model describes the data with an average error of about $25 \%$, which is larger than for two of the individual data sets.

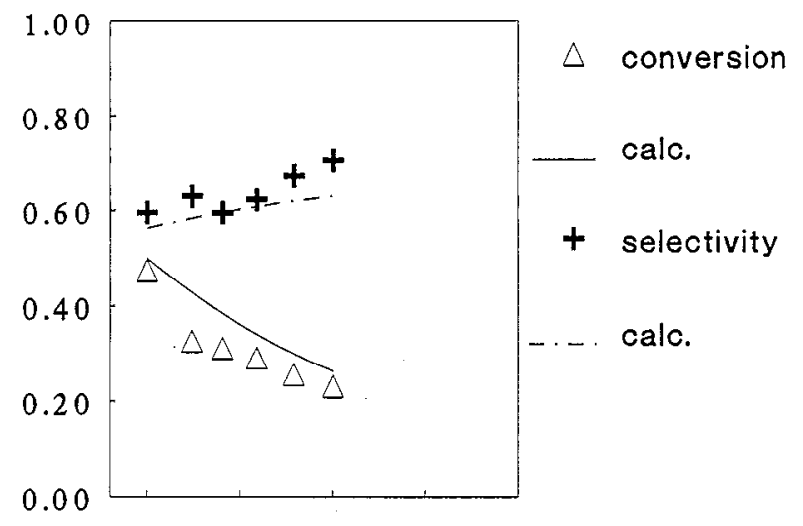

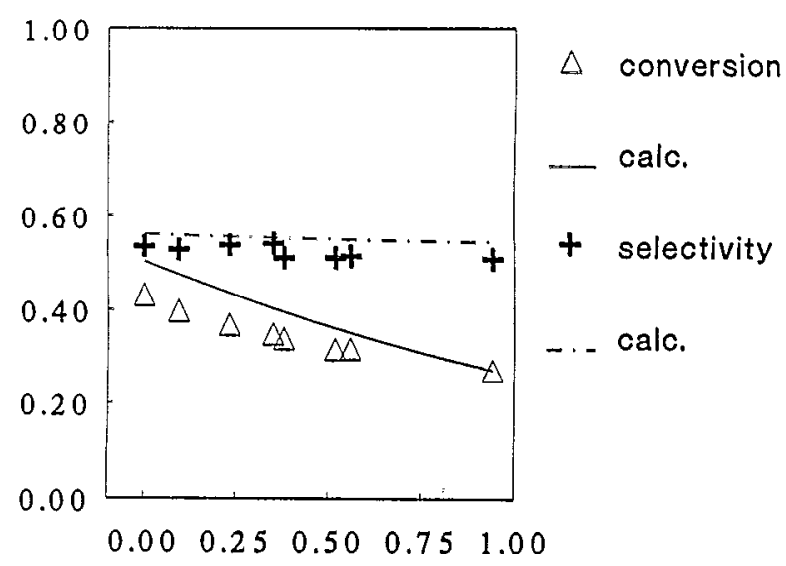

(a)

water conc./mol \%

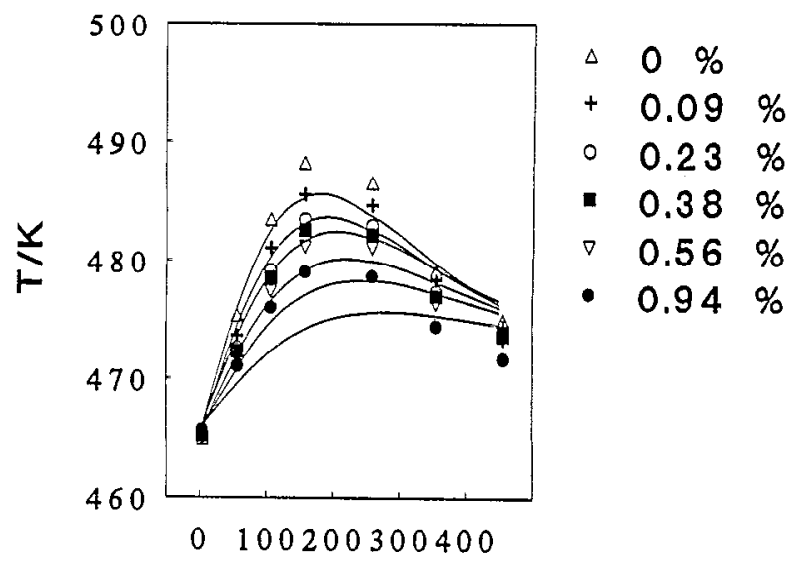

(b)

axial position $/ \mathrm{mm}$

Fig, 9. Influenre of the additing of $\mathrm{H}_{\Omega} \Omega$ on the ronsersion and

tions: $T_{\mathrm{w}}=465 \mathrm{~K}, \phi_{\mathrm{m}}=0.84 \mathrm{~kg} \mathrm{~m}^{-2} \mathrm{~s}^{-1}, P=0.5 \mathrm{MPa}$ and $x_{\mathrm{E}, \mathrm{in}}=0.5 \mathrm{~mol} \%$.

The reaction products inhibit the rates of epoxidation and total combustion. Carbon dioxide enhances the selectivity, whereas water has almost no influence. Large values for the fitted ethene oxide kinetic constants are probably a result of the fitting procedure where the different data sets are forced to correspond.

The reaction rate expressions used in the reactor model give unsatisfactory results when describing the temperature profiles in a wall-cooled, packed-bed reactor in which products have been added to the feed. Although the trends are predicted reasonably well, the calculated conversions are too large and the axial temperature profiles are too flat. Although the uncertainty in the kinetics may explain these two phenomena, the rate expressions should be changed fundamentally to predict a smaller conversion and a more pronounced temperature profile at the same time if the description of heat transport in the model is correct. 


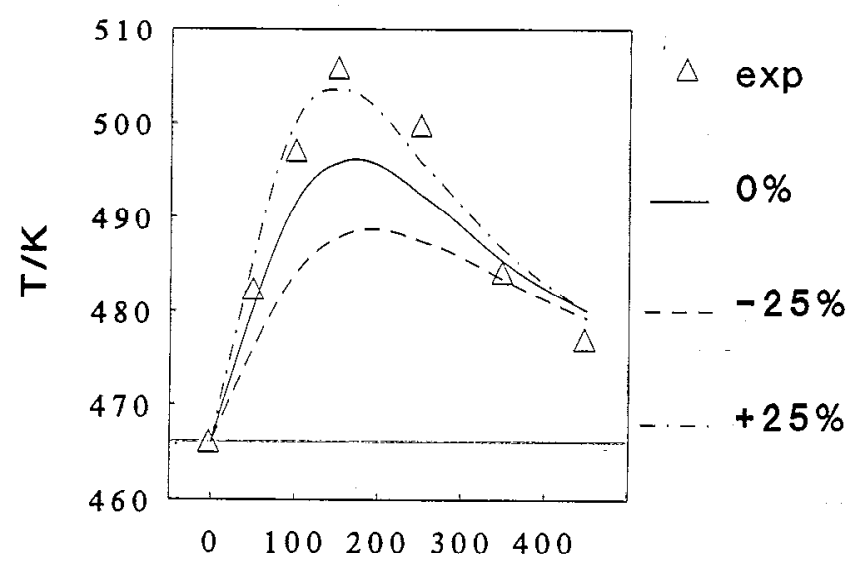

axial position $/ \mathrm{mm}$

Fig. 10. Influence of a change in frequency factor on the calculated axial temperature profile in the centre of the tube (see also Table 8). Conditions: $T_{\mathrm{w}}=466 \mathrm{~K}, \phi_{\mathrm{m}}=0.83 \mathrm{~kg} \mathrm{~m}^{-2} \mathrm{~s}^{-1}, P=0.5 \mathrm{MPa}$ and $x_{\mathrm{E}, \text { in }}=0.715 \mathrm{~mol} . \%$.

\section{Acknowledgements}

We gratefully acknowledge the technical assistance of K. v. Bree, F. t. Borg, A.H. Pleiter and O.D. Veehof and the experimental work of J.H. Hendriks and W.F. Hendriksen.

\section{Appendix: Nomenclature}

$d_{\mathrm{t}} \quad$ tube diameter $(\mathrm{m})$

$E$ activation energy $\left(\mathrm{J} \mathrm{mol}^{-1}\right)$

$f$ average error

$k_{\mathrm{r}} \quad$ reaction rate constant $\left(\mathrm{mol} \mathrm{s}^{-1}(\mathrm{~kg} \text { catalyst })^{-1}\right)$

$k_{\mathrm{r}, \infty}$ pre-exponential constant (mol s${ }^{-1}$ (kg catalyst) ${ }^{-1}$ )

$K \quad$ adsorption constant $\left(\right.$ bar $\left.^{-1}\right)$

$K_{j, \infty}$ pre-exponential adsorption factor $\left(\right.$ bar $^{-1}$ )

$L \quad$ reactor length $(\mathrm{m})$

$N$ total number of experiments

$P \quad$ pressure (bar)

$r$ reaction rate (moles $j$ produced $\mathrm{s}^{-1}(\mathrm{~kg}$ catalyst $)^{-1}$ )

$R$ production rate (moles $j$ produced $\mathrm{s}^{-1}$ ( $\mathrm{kg}$ catalyst $)^{-1}$ )

$S \quad\left(=\left(R_{\exp }-R_{\text {calc }}\right) / R_{\exp }\right)$, relative residual

Table 8

Influence of a change in frequency on tubular reactor performance (see Fig. 10 for conditions)

\begin{tabular}{lll}
\hline & $\zeta$ & $\sigma$ \\
\hline Experimental & 0.392 & 0.588 \\
Calculated & 0.488 & 0.536 \\
Frequency factor $\times 0.75$ & 0.397 & 0.548 \\
Frequency factor $\times 1.25$ & 0.566 & 0.522 \\
\hline
\end{tabular}

$T$ temperature $(\mathrm{K})$

$T_{\text {act }}(=E / R)$, activation temperature $(\mathrm{K})$

$T_{\text {ads }}(=\Delta H / R)$, adsorption temperature $(\mathrm{K})$

$x$ mole fraction

$z \quad$ axial position (m)

Greek symbols

$\phi_{\mathrm{m}} \cdot \operatorname{mass}$ flux $\left(\mathrm{kg} \mathrm{m}^{-2} \mathrm{~s}^{-1}\right)$

$\Delta H$ heat of reaction or heat of adsorption $\left(\mathrm{J} \mathrm{mol}^{-1}\right)$

Subscripts and superscripts

act activation

ads adsorption

C carbon dioxide

calc calculated

$E$ ethene

EO ethene oxide

exp experimental

$i$ of reaction $i$

in inlet

$j \quad$ of component $j$

$\mathrm{O}$ oxygen

w wall

W water

1 epoxidation reaction

2 total combustion reaction

3 ethene oxide combustion reaction

\section{References}

[1] E.P.S. Schouten, P.C. Borman and K.R. Westerterp, Determination of the kinetics of the ethene epoxidation, Chem. Eng. Proc., submitted for publication.

[2] M. Stoukides and S. Pavlou, Ethylene oxidation on silver catalysts: effect of ethylene oxide and of external transfer limitations, Chem. Eng. Commun., 44 (1986) 53-74.

[3] R.A. v. Santen and H.P.C.E. Kuipers, The mechanism of the ethylene epoxidation, Adv. Catal., 35 (1987) 265-321.

[4] P.C. Borman and K.R. Westerterp, An experimental study of the kinetics of the selective oxidation of ethene over a silver on a-alumina catalyst, Ind. Eng. Chem. Res., 34 (1995) 49-58.

[5] M.I. Temkin, The kinetics of some industrial heterogeneous catalytic reactions, Adv. Catal., 28 (1979) 173-290.

[6] C. Backx, J. Moolhuysen, P. Geenen and R.A. v. Santen, Reactivity of oxygen adsorbed on silver powder in the epoxidation of ethylene, J. Catal., 72 (1981) 364-368.

[7] R. Hall and G. Neubauer, Kinetic studies on the mechanism of the catalytic ethene oxidation, J. Catal, 105 (1987) 39-54.

[8] H. Worbs, Ph.D. Thesis, Technische Hochschule, Breslau, 1942.

[9] R.E. Kenson and M. Lapkin, Kinetics and mechanism of ethylene oxidation. Reaction of ethylene and ethylene oxide on a silver catalyst, J. Phys. Chem., 74 (1970) 1493-1502.

[10] P.A. Kilty and W.M.H. Sachtler, The mechanism of the selective oxidation of cthylenc to cthylcne oxide, Cat. Rev. Sci. Eng., 10 (1974) $1-16$.

[11] N.W. Cant and W.K. Hall, Catalytic oxidation VI. Oxidation of labelled olefins over silver, J. Catal., 52 (1978) 82-94.

[12] S. Kagawa, M. Iwamoto, H. Mori and T. Seiyama, Formation 
of adsorbed oxygen and its reactivity with ethylene over silver catalysts, J. Phys. Chem, 85 (1981) 434-439.

[13] W. Bremer, Untersuchung zum Einfluß der periodischen Prozeßführung auf das Temperaturfeld im Festbettreaktor, Thesis, TU Clausthal, 1982.

[14] C.T. Campbell, The selective epoxidation of ethylene catalysed by $\operatorname{Ag}(111)$ : a comparison with $\operatorname{Ag}(110), J$. Catal., 94 (1985) 436-444.

[15] L. Petrov, A. Eliyas and D. Shopov, A kinetic model of steady state ethylene epoxidation over a supported silver catalyst, Appl. Catal., 18 (1985) 87-103.

[16] D.W. Park and G. Gau, Ethylene epoxidation on a silver catalyst: unsteady and steady state kinetics, J. Catal., 105 (1987) 81-94.

[17] E.A. Carter and W.A. Goddard III, The surface atomic oxyradical mechanism for Ag-catalyzed olefin epoxidation, J. Catal., 112 (1988) 80-92.

[18] E.L. Force and A.T. Rell, Infrared spectra of adsorbed species present during the oxidation of ethylene over silver, J. Catal., 38 (1975) 440-460.

[19] E.L. Force and A.T. Bell, The relationship of adsorbed species observed by infrared spectroscopy on the mechanism of ethylene oxidation over silver, J. Catal., 40 (1975) 356-371.

[20] R.B. Grant, C.A.J. Harbach, R.M. Lambert and S.A. Tan, Alkali metal, chlorine and other promoters in the silver-catalysed selective oxidation of ethylene, J. Chem. Soc., Faraday Trans., 83 (1987) 2035-2046.

[21] J.T. Gleaves, A.G. Sault, R.J. Madix and J.R. Ebner, Ethylene oxidation on silver powder: a TAP reactor study, J. Catal., 121 (1990) 202-218.

[22] B. Griffe, E. Blues and D. Bryce-Smith, Study of the effect of carbon dioxide on the catalytic properties of a silver catalyst in the oxidation of ethylene to ethylene oxide, Appl. Catal., 10 (1984) 303-312.

[23] L.E. Wachs and S.R. Keleman, The interaction of ethylene with surface carbonate and hydroxide intermediates on silver, $J$. Catal., 71 (1981) 78-87.

[24] S.A. Tan, R.B. Grant and R.M. Lambert, Pressure dependence of ethylene oxidation kinetics and the effect of added $\mathrm{CO}_{2}$ and Cs: a study on $\mathrm{Ag}(111)$ and $\mathrm{Ag} / \alpha-\mathrm{Al}_{2} \mathrm{O}_{3}$ catalysts, Appl. Catal., 31 (1987) 159-177.

[25] D.A. Bulushev and A.V. Khasin, Effect of carbon dioxide on the catalytic oxidation of ethylene over silver. Kinetic reaction model accounting for the modification of catalyst surface by carbonate groups, React. Kinet. Catal. Lett., 44 (1991) 463-468.
[26] G.R. v. Schultze and H. Theile, Ưber die Oxydation von Äthylen in der Gasphase an Silberkontakten, Erdöl tund Kohle, 5 (1952) $552-560$.

[27] K.E. Hayes, The role of reaction products in the silver catalyzed oxidation of ethylene, Can. J. Chem, 38 (1960) 2256-2268.

[28] J. Mikami, S. Satoh and H. Kobayashi, Studies on the catalytic oxidation of ethylene by means of the pulse technique, J. Catal., 18 (1970) 265-270.

[29] D.A. Bulushev and A.V. Khasin, Effect of carbon dioxide on the catalytic oxidation of ethylene over silver. Reaction rates and composition of adsorbed layer, React. Kinet. Catal. Lett., 44 (1991) 421-425.

[30] L.G. Nault, D.W. Bolme and L.N. Johanson, Reaction rate studies of catalytic oxidation of ethylene, Ind. Eng. Chem. Proc. Des. Dev., 1 (1962) 285-292.

[31] M.A. Al-Saleh, M.S. Al-Ahmadi and M.A. Shalabi, Kinetic study of ethylene oxidation in a Berty reactor, Chem. Eng. J., 73 (1988) 35-41.

[32] P.L. Metcalf and P. Harriot, Kinetics of silver-catalysed ethylene oxidation, Ind. Eng. Chem. Proc. Des. Dev., 11 (1972) 478-484.

[33] A. Eliyas and L. Petrov, Modelling of the inhibiting effect of carbon dioxide on the selective oxidation of ethene over silver catalyst, Appl. Catal., 62 (1990) 11-21.

[34] M. Bowker, M.A. Barteau and R.J. Madix, Oxygen induced adsorption and reaction of $\mathrm{H}_{2}, \mathrm{H}_{2} \mathrm{O}, \mathrm{CO}$ and $\mathrm{CO}_{2}$ on single crystal Ag(110), Surf. Sci., 92 (1980) 528-548.

[35] W. Liu, A. Eliyas and L. Petrov, Influence of feed water vapour on the selective oxidation of ethylene over silver catalyst, Appl. Catal., 61 (1990) 265-274.

[36] K.E. Murray, A study of the oxidation of ethylene on a silver catalyst, Austr. J. Sci., Ser. A, 3 (1950) 433-449.

[37] P.D. Klugherz and P. Harriot, Kinetics of ethylene oxidation on a supported silver catalyst, $A I C h E J ., 17$ (1971) 856-866.

[38] J.M. Berty, Reactors for vapour-phase catalytic studies, Chem. Eng. Proc., 70 (1974) 78-84.

[39] P.C. Borman, A.N.R. Bos and K.R. Westerterp, A novel reactor for determination of kinetics for solid catalysed gas reactions, AIChE J., 40 (1994) 862-869.

[40] E.P.S. Schouten, P.C. Borman and K.R. Westerterp, Oxidation of ethene in a wall cooled tubular reactor, Chem. Eng. Sci., in press.

[41] E.C. Steiner, T.D. Rey and P.S. McCroskey, SIMUSOLV Reference Guide, Dow Chemical Company, 1990.

[42] R.K. Sharma, D.L. Cresswell and E.J. Newson, Kinetics and fixed-bed reactor modelling of butane oxidation to maleic anhydride, AIChE J., 37 (1991) 39-47. 